\title{
Ablation behaviors of carbon reinforced polymer composites by laser of different operation modes
}

\author{
Chen-Wu Wu*, Xian-Qian Wu, Chen-Guang Huang \\ Institute of Mechanics, Chinese Academy of Sciences, Beijing 100190, China
}

\section{A R T I C L E I N F O}

\section{Article history:}

Received 24 January 2015

Received in revised form

9 April 2015

Accepted 10 April 2015

Available online 14 May 2015

Keywords:

Laser ablation

CFRP laminates

Operation modes

\begin{abstract}
A B S T R A C T
Laser ablation mechanism of Carbon Fiber Reinforced Polymer (CFRP) composite is of critical meaning for the laser machining process. The ablation behaviors are investigated on the CFRP laminates subject to continuous wave, long duration pulsed wave and short duration pulsed wave lasers. Distinctive ablation phenomena have been observed and the effects of laser operation modes are discussed. The typical temperature patterns resulted from laser irradiation are computed by finite element analysis and thereby the different ablation mechanisms are interpreted.
\end{abstract}

(c) 2015 Elsevier Ltd. All rights reserved.

\section{Introduction}

Carbon Fiber Reinforced Polymer (CFRP) composites are widely used to make many high strength-weight ratio parts, especially in a great many of aero structures [1]. Even being developed with the near-net forming characteristic, the CFRP composite products always need further necessary machining, wherein the classic machining is greatly challenged for the relatively low efficiency and the probability of damaging the work pieces [2]. As an inborn flexible alternative, laser machining of CFRP materials has drawn much attention, in which laser cutting and drilling are the most typical applications [3]. In such processing, laser energy is designed to be absorbed by the target materials and dissipated into thermal energy quickly. Therefore, in order to improve the process quality as well as reduce energy consumption, it is natural to hope the thermal energy to be largely confined to a small specific region to only make the materials therein evaporate without affecting the adjacent region [4]. In physics, this actually requires high spatial and temporal concentration of the laser energy, which could be realized through focusing the laser beam and shortening the laser duration [5]. From such point of view, one can immediately understand that the laser energy would be greatly wasted as too much material is heated up beyond the objective region if the laser power density is too low or the exposure duration is too long [6,7]. While it is not so commonly recognized that too concentration of laser energy might also lead

\footnotetext{
* Correspondence to: No.15 Bei Si Huan Xi Road, Hai Dian District, Beijing 100190, China Tel.: +86108254 4271.

E-mail address: chenwuwu@imech.ac.cn (C.-W. Wu).
}

to energy waste and even failure in processing. This is because large part of the incident laser energy would be dissipated in the plasma layer near the target surface when optical breakdown is intrigued by very high power density laser [8-10]. As a matter of fact, the threshold of such optical breakdown has been theoretically predicted well for clean air and experimentally obtained for classical target materials [11-13]. However, no direct reference data in relevance to optical breakdown has been reported for CFRP composites according to our knowledge. Moreover, no comparison work has been found to describe the difference in the ablation mechanisms on the CFRP composites subjected to continuous wave laser to pulsed wave laser. It is natural to expect that distinctive ablation patterns would arise in the specimens under irradiation by differently operated lasers, which determine the spatial and temporal distribution characteristics of the light energy $[7,14]$. Therefore, the basic knowledge should be developed to justify the application of laser machining to CFRP composites parts. To reveal the principle thermo-physical responses of the CFRP composites to the irradiation by continuous wave laser or pulsed wave laser and, to explore the laser parameter range appropriate to the laser machining of CFRP materials, the present work designed and carried through several groups of laser irradiation tests on CFRP specimens. The typical ablation behaviors and morphologies of the CFRP specimens irradiated by the Nd:YAG continuous wave laser, long duration pulsed wave laser or short duration pulsed wave laser have been revealed and, the effects of the laser power temporal pattern on that been discussed. Temperature patterns of the CFRP laminates under irradiation by the continuous wave, long duration pulsed wave and short duration pulsed wave lasers are analyzed by finite element method. 
Thereby, the differences in laser ablation mechanisms of CFRP laminates are interpreted.

\section{Experimental and model description}

The laser setups used in the experiment are shown in Fig. 1 and the laser parameters are listed in Table 1. Fig. 1(a) represents the Nd:YAG continuous wave laser (denoted by CW) and Fig. 1(b) the Nd:YAG pulsed wave laser. Two modes, i.e. pulse duration of 200 ns (long pulse duration, denoted by LP) and $10 \mathrm{~ns}$ (short duration, denoted as SP), of the pulsed wave laser were adopted in test. The polarizations of both the continuous wave laser and pulsed wave laser are random. The total exposure times are $10 \mathrm{~s}$ for all of the three kinds of irradiation tests. Thereafter, the surface and cross-section morphology were examined by using a Zeiss Stemi SV11 optical microscope. Moreover, the three dimensional (3-D) sketches were drawn by the computer aided design (CAD) software to describe the ablation appearances.

Square CFRP specimens were prepared as shown in Fig. 2(a), in which plain woven carbon fiber cloth (T800) reinforced polymer (Epoxy 5228A) laminate were laid up to make CFRP laminate of dimensions $50 \mathrm{~mm} \times 50 \mathrm{~mm} \times 4.1 \mathrm{~mm}$ and an axis-symmetrical finite element model was set up as shown in Fig. 2(b) to analyze the thermo-physical responses of the specimens. In Fig. 2(b), $L$ represents the radius of the cross-section, $t=4.1 \mathrm{~mm}$ the total thickness of the specimen, $t_{\mathrm{c}}=0.1 \mathrm{~mm}$ the carbon fiber layer thickness and $t_{\mathrm{e}}=0.4 \mathrm{~mm}$ the epoxy matrix thickness in every laminate.

As a preliminary study, one could ignore the flow of the sublimation product and write the heat conduction equation as

$\rho \mathrm{C}_{\mathrm{p}} \frac{\partial T}{\partial t}=\nabla \cdot(k \nabla T)+Q_{\mathrm{vh}}$

within the domain with the thermal boundary conditions of

$q_{1}=q$

at the surface range of $z=4.1 \mathrm{~mm}$ and $r<r_{0}$, the focus spot radius,

$q_{\mathrm{c}}=h\left(T-T_{\mathrm{en}}\right)$

and

$q_{\mathrm{r}}=\varepsilon \sigma T^{4}$

at the entire outer surfaces, where $T$ is the temperature, $t$ is the time, $\rho$ is the density, $C_{\mathrm{p}}$ is the specific heat capacity, $k$ is the thermal conductivity, $Q_{\mathrm{vh}}$ is the vaporization latent heat during sublimation, $q_{1}$ is the incident laser power density, $q_{\mathrm{c}}$ is the heat dissipated into the environment of temperature $T_{\text {en }}=293 \mathrm{~K}$ through free air convection, $q_{\mathrm{r}}$ is the heat flux flow into the environment through surface thermal radiation, $h=30 \mathrm{~W} / \mathrm{m}^{2} / \mathrm{K}$ the natural convection heat transfer coefficient, $\varepsilon=0.8$ the surface emissivity and $\sigma=5.67 \times 10^{-8} \mathrm{~W} / \mathrm{m}^{2} / \mathrm{K}^{4}$ the Stephan Boltzmann constant.

The basic thermo-physical parameters of the carbon fiber and epoxy matrix are listed in Table 2, in which the subscript ' $s$ ' represents the solid phase while 'g' the gas phase. The gas phases are approximately treated to be trapped in the origin locations while no pressure effects have been involved in the model. The optical absorbance in the sample should be inhomogeneous, because the absorbance characteristics are different for the epoxy matrix and the plain carbon fiber fabric layer in the sample. However, homogeneous absorbance of laser in the sample was assumed in the present numerical modeling to simplify the theoretical work. Furthermore, the laser energy is assumed to be absorbed through the most upper surface of the specimen all along. Therefore, the horizontal thermal conductivity of the gas phase $\left(k_{\mathrm{g} \rightarrow}\right)$ is set very small while its vertical thermal conductivity $\left(k_{\mathrm{g} \downarrow}\right)$ is exaggerated to be very large to simulate the downward movement of the top surface absorbing the laser energy. One can imagine that the gas phase shall continue absorb laser energy and get further temperature elevation. It is to a large extent reasonable, in particular, for the situations that only very short time spans are considered as the gas would have no enough time to escape.

\section{Results and discussion}

The surface morphologies are shown in Fig. 3. The cross-section profiles are provided in Fig. 4, in which Fig. 4(a-1), (b-1) and (c-1) is photographed by optical microscope and, Fig. 4(a-2), (b-2) and (c-2) is drawn by CAD software.

Figs. 3(a) and 4(a) show that the continuous wave laser irradiation has ablated through several layers of the CFRP laminate. And many voids arise in the epoxy layer remained after laser irradiation for $10 \mathrm{~s}$ as shown in Fig. 3(a-2), which indicates that the

Table 1

Parameters of laser beam and irradiation test.

\begin{tabular}{llll}
\hline & CW & LP & SP \\
\hline Wavelength $(\mathrm{nm})$ & 1064 & 1064 & 1064 \\
Focus spot radius $\left(r_{0}\right)(\mathrm{mm})$ & 3 & 1.5 & 1.5 \\
Power or pulse energy & Power $100 \mathrm{~W}$ & $2.0 \mathrm{~J}$ & $2.0 \mathrm{~J}$ \\
Pulse duration $(\mathrm{ns})$ & - & 200 & 10 \\
Repeat frequency $(\mathrm{Hz})$ & - & $10 \mathrm{~Hz}$ & $10 \mathrm{~Hz}$ \\
Power density $(q)\left(\mathrm{W} / \mathrm{m}^{2}\right)$ & $3.54 \times 10^{6}$ & $1.50 \times 10^{12}$ & $3.00 \times 10^{13}$ \\
Mean power density $\left(q_{\text {ave }}\right)\left(\mathrm{W} / \mathrm{m}^{2}\right)$ & $3.54 \times 10^{6}$ & $2.94 \times 10^{6}$ & $2.94 \times 10^{6}$ \\
Exposure time $(t)(\mathrm{s})$ & 10 & 10 & 10 \\
\hline
\end{tabular}

b
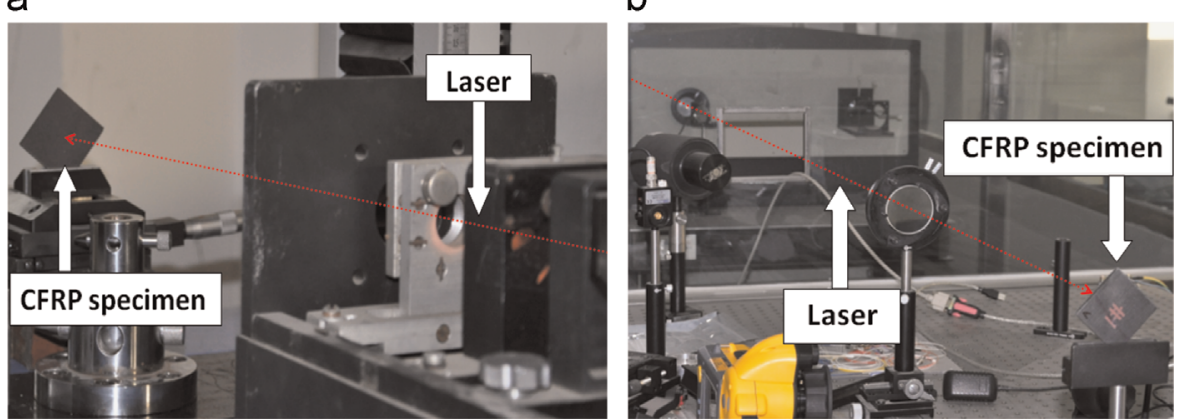

Fig. 1. (a) Continuous wave laser and (b) pulsed wave laser setups for irradiation test. 
a

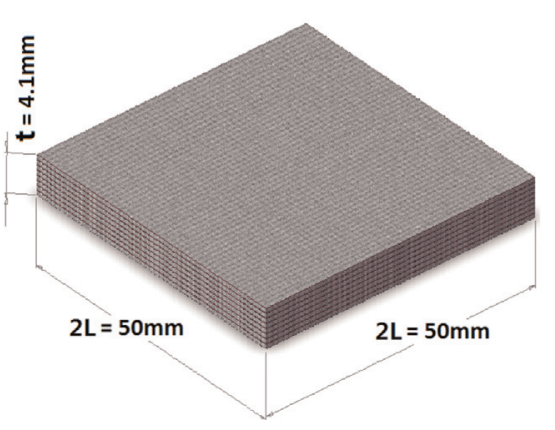

b

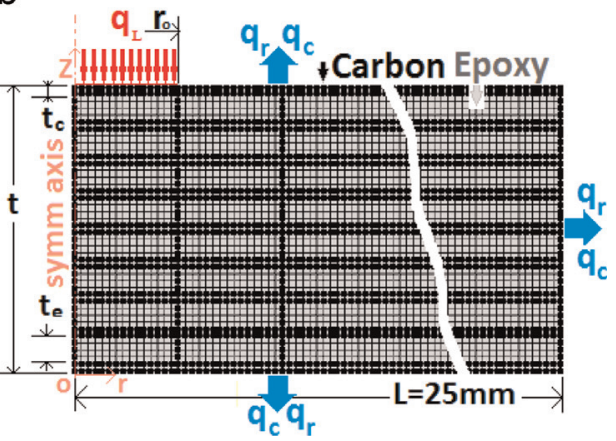

Fig. 2. (a) Sketch of the CFRP laminate specimen and (b) FEA model.

Table 2

Thermo-physical parameters of the materials $[15,16]$.

\begin{tabular}{|c|c|c|c|c|c|c|c|}
\hline & \multirow[t]{2}{*}{ Density $\left(\mathrm{kg} / \mathrm{m}^{3}\right)$} & \multirow[t]{2}{*}{ Specific heat (J/kg K) } & \multicolumn{3}{|c|}{ Thermal conductivity $(\mathrm{W} / \mathrm{m} \mathrm{K})$} & \multirow[t]{2}{*}{ Sublimation temperature (K) } & \multirow[t]{2}{*}{ Vaporization latent heat $(\mathrm{kJ} / \mathrm{kg})$} \\
\hline & & & $k_{\mathrm{s}}$ & $k_{\mathrm{g} \rightarrow}$ & $k_{\mathrm{g} \downarrow}$ & & \\
\hline Carbon & 1850 & 710 & 50 & {$[0.1]$} & [1000] & 3600 & 43,000 \\
\hline Epoxy & 1200 & 1100 & 0.1 & [0.1] & [1000] & 700 & 1100 \\
\hline
\end{tabular}

a1

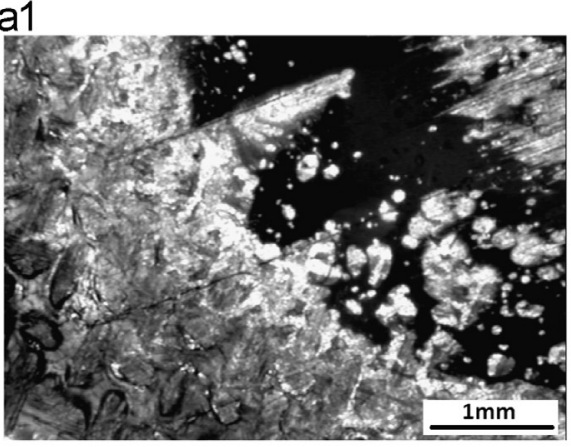

b1
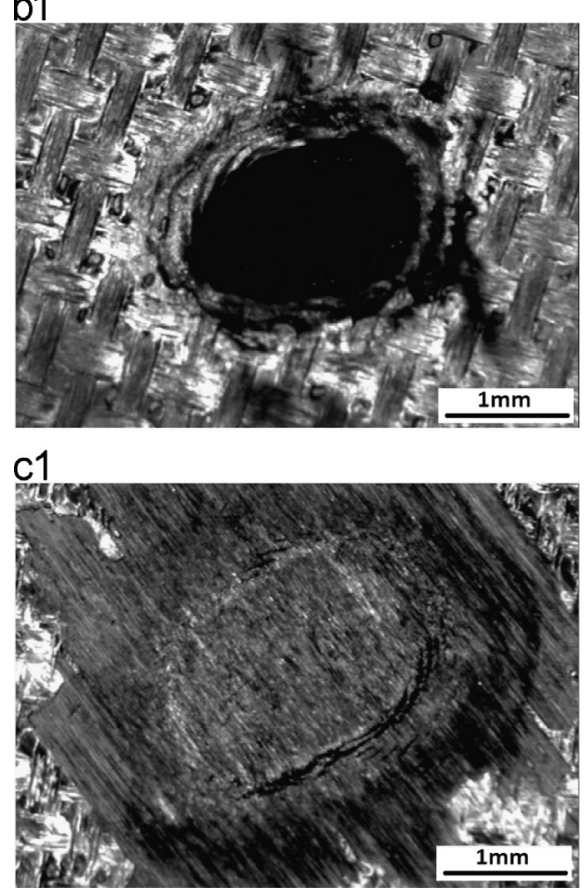

a2

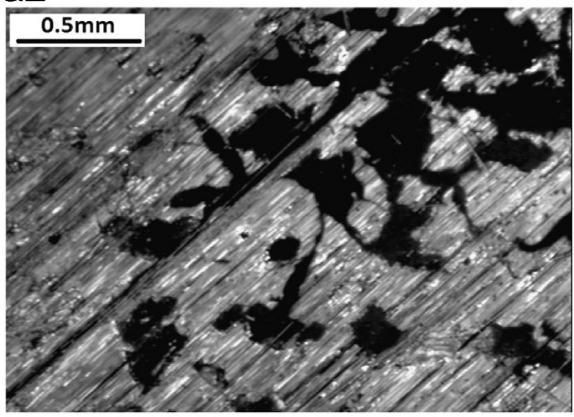

b2

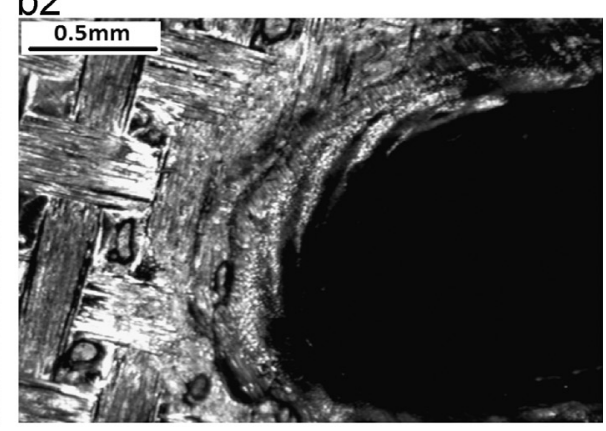

c2

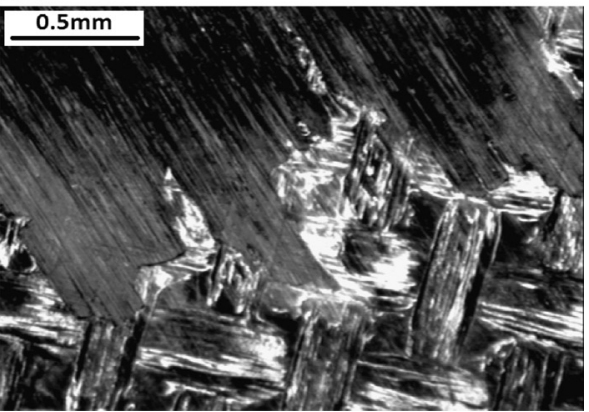

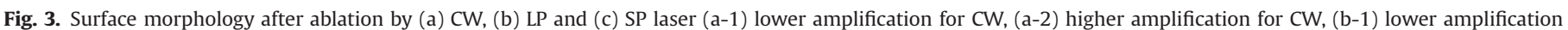
for LP, (b-2) higher amplification for LP, (c-1) lower amplification for SP, and (c-2) higher amplification for SP. 
a1

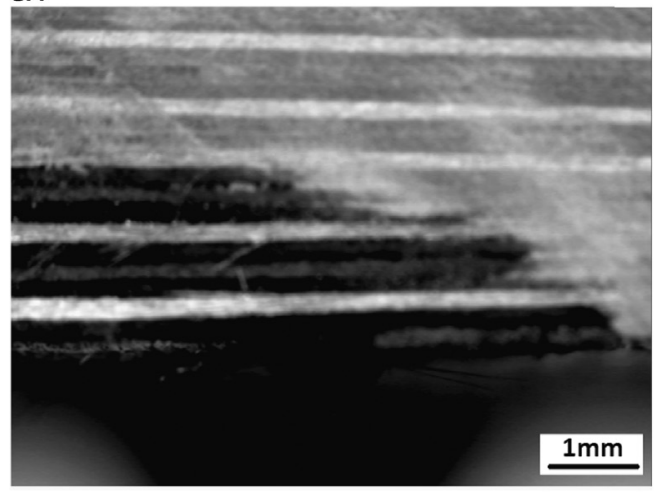

b1

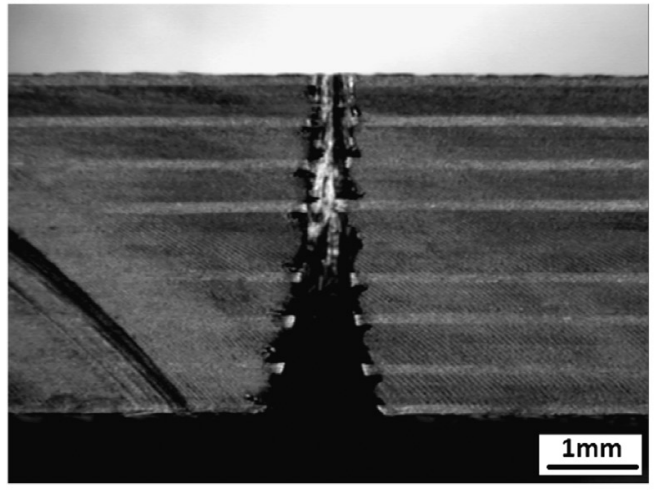

c1

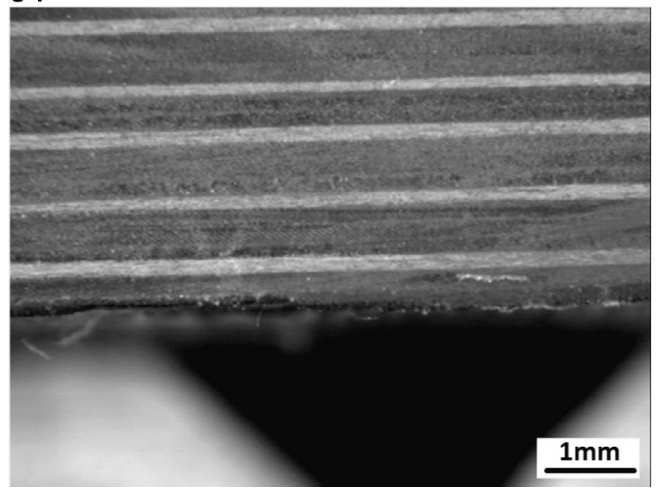

a2

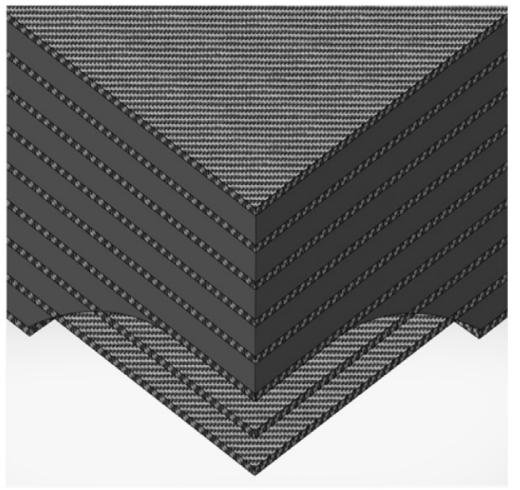

b2

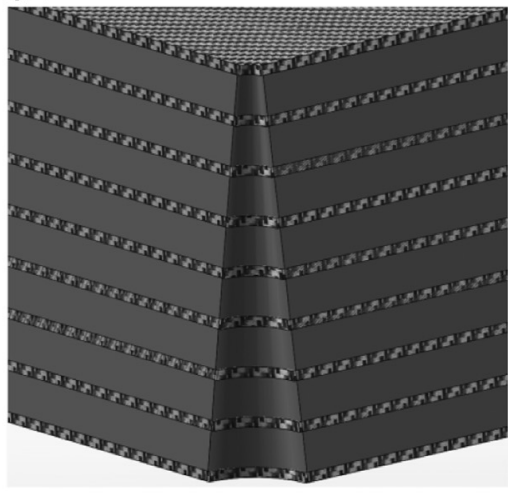

c2

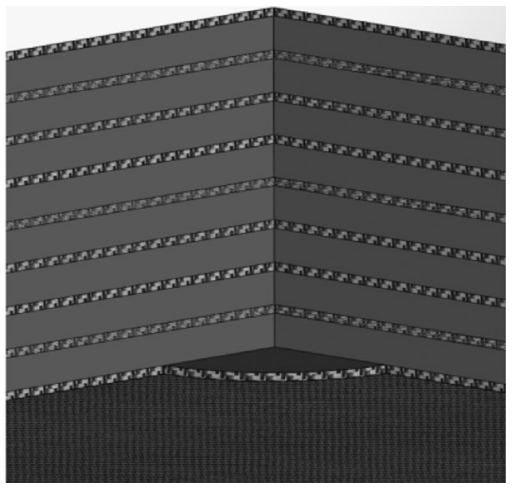

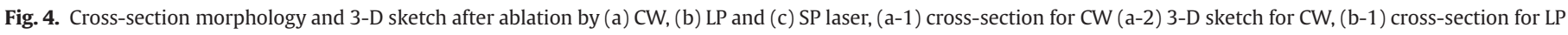
(b-2) 3-D sketch for LP, (c-1) cross-section for SP (c-2) 3-D sketch for SP.

ablation could be continued if the laser irradiation is maintained. One can see in Fig. 3(a-1) that the surface carbon fiber fabric has been circularly cut and relative complex morphology appears around the edge region. However, one can also see in Fig. 4(a) that the carbon fibers have not been ablated even though several layers of epoxy been removed by laser irradiation. This is perhaps due to that the evaporation of epoxy matrix brings away much of the incident laser energy and thereby the carbon fiber temperature is always lower than its sublimation point. Moreover, the radius of the near circular ablation region is about $6 \mathrm{~mm}$, nearly twice the radius of the laser beam, which indicates that the transverse heat conduction makes apparent contribution to the process.

Figs. 3(b) and 4(b) show that the long duration pulsed wave laser irradiation has made a conical hole through the laminate. The largest radius of the conical hole is about $1 \mathrm{~mm}$, which is smaller than the laser beam radius. It looks like that every carbon fiber cloth layer has been cut off very clearly along the conical hole wall. It is implied that there should have been great temperature gradient over the spot covered region. Because, as shown in Figs. 3(b) and 4(b), the edge between the origin material and the ablation region is very clear, which indicates that the heat affected zone is rather limited. Such ablation characteristic would be welcome in laser machining of CFRP composites, as the material is removed clearly from the objective region without developing too much negative influence to the adjacent regime.

In comparison, the short duration pulsed wave laser irradiation has not led to much ablation other than ablation of the thin surface carbon fabric as shown in Figs. 3(c) and 4(c). The ablation region edges of the surface carbon fabric are very irregular with the average radius of the ablated region in the surface fabric layer being about $2 \mathrm{~mm}$, which is slightly larger than the laser spot radius. However, the under epoxy laminate closely attached to the top carbon fabric has not been ablated obviously with only a faint elliptic trace being left on its surface. This should have been due to 
the fact that the laser-induced plasma absorbs large part of the incident laser energy as air breakdown arises before the specimen after the surface carbon fiber fabric locally evaporates. Essentially the gasified carbon fiber would contaminate the air around the target and change the clean air into polluted atmosphere. As we know, the theoretical threshold of power flux in $\mathrm{W} / \mathrm{m}^{2}$ for the breakdown of clean air is [11]

$q_{\mathrm{tb}}=1.44 \times 10^{10}\left(p^{2}+2.2 \times 10^{5} \lambda^{-2}\right)$

with $p$ being the pressure in standard atmospheric pressure and $\lambda$ the laser wavelength in micrometers, although it was verified that this prediction overestimates the breakdown power by at least one order of magnitude in some situations [11]. Furthermore, this threshold would be obviously reduced by the pollutant such as ablation product $[8,10]$. For instance, it was reported that over 80 percent of the pulsed wave Nd:YAG laser energy would be dissipated in the plasma layer before the stainless steel target once the incident power density is above $4.4 \times 10^{12} \mathrm{~W} / \mathrm{m}^{2}$ [9].

As we know, the ablation effect of the target material is strongly dependent on deposited energy, i.e. the light energy absorbed by the target material. However, the percentage of light energy arrived at the target surface would be largely dependent on the circumstance status before the target. A large part of the laser energy would be held back from the target once the Plasmon density falls into some specific range. Therefore, it is reasonable to guess that the threshold of laser power density to intrigue optical breakdown before the present CFRP target should fall into the range through $1.5 \times 10^{12}-3.0 \times 10^{13} \mathrm{~W} / \mathrm{m}^{2}$. Although such prediction is somewhat approximate and the range is a little wide, it is certain that the pulsed wave laser of power density less than $1.5 \times 10^{12} \mathrm{~W} / \mathrm{m}^{2}$ might be appropriate for laser machining of the CFRP laminates of properties as presented herein. In contrast, it is definitely inefficient to adopt the pulsed wave laser of power density greater than $3.0 \times 10^{13} \mathrm{~W} / \mathrm{m}^{2}$.

By utilizing the finite element model as shown in Fig. 2, the numerical computation is carried through $10 \mathrm{~s}$ for continuous wave laser, while $0.1 \mathrm{~s}$ for the pulsed wave laser with the minimum time step being $0.25 \mathrm{~ns}$ to include one round of heating and cooling. During the cooling stage the heat diffusion is realized principally through thermal conduction within the specimen, natural convection and thermal radiation as described by Eqs. (1)-(4), while as latent heat would account for due to phase change during the heating stage. The temperature histories and profiles of the specimens are shown in Fig. 5 for the three cases, in which Fig. 5(a)-(c) is in sequence corresponding to that of continuous wave laser, long duration pulsed wave laser and short pulsed wave laser respectively.
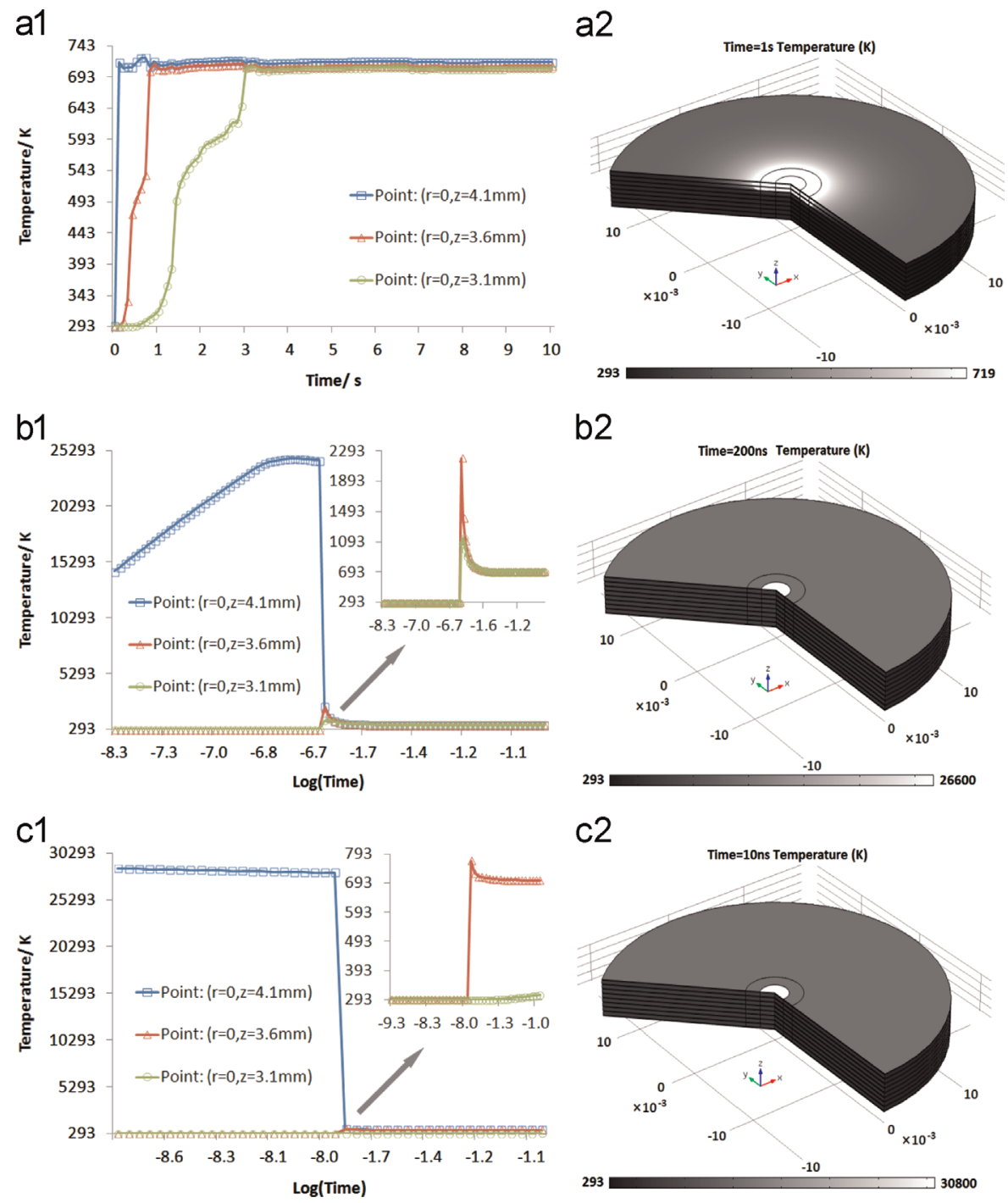

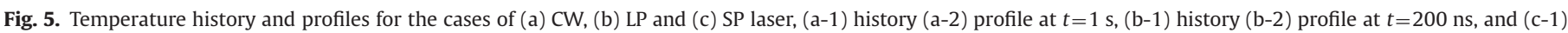
history (c-2) profile at $t=10 \mathrm{~ns}$. 
It is to be noted that the logarithm of time is used as abscissa in Fig. 5 (b-1) and (c-1) to avoid lengthy numbers.

Fig. 5(a-1), (b-1) and (c-1) shows the temperature histories of the three center points located at the top $(r=0, z=4.1 \mathrm{~mm})$, second $(r=0, z=3.6 \mathrm{~mm})$ and third $(r=0, z=3.1 \mathrm{~mm})$ carbon layers with the abscissa being $\log$ (time) for the pulsed wave laser irradiation cases. And the temperature history curves are partially magnified and shown in the upper right corner in Fig. 5(b-2) and (c-1). Fig. 5(a-2), (b-2) and (c-2) shows the axisymmetric temperature profiles of the three specimens at the instants of $1.0 \mathrm{~s}$, $200 \mathrm{~ns}$ or $10 \mathrm{~ns}$. The results show that the peak temperature in the specimen developed by the continuous wave laser is about $719 \mathrm{~K}$, which is around the sublimation temperature of the epoxy matrix. The peak temperature developed by the long duration pulsed wave laser and short duration pulsed wave laser is $26,600 \mathrm{~K}$ and $30,800 \mathrm{~K}$, respectively, which is consistent with the reported experimentally measured electron temperature in laser induced plasma [17], at least by the order of magnitude.

It is also revealed that the peak temperature would be stabilized around the sublimation point of the epoxy matrix under the irradiation of continuous wave laser. While as for the cases of pulsed wave laser irradiation, the first pulse would lead to ultra-high temperature (over $25,000 \mathrm{~K}$ ) in the top carbon fabric layer, although the temperature returns and stabilizes around the sublimation point of the epoxy matrix soon after the end of the pulse. It is believable that the top carbon fiber fabric evaporates upon the first laser pulse, for the cases of both long duration and short duration. Moreover, the sublimation of the carbon fiber might have been followed by the quick growth of Plasmon due to the subsequent irradiation by the short duration pulsed laser. And the Plasmon density before the target under irradiation of the short pulsed wave laser should have been high enough to hold back the laser from further influencing the target in the present test period. It is noteworthy that, although the numerical results on the cases of short pulsed wave laser have revealed an extreme high temperature in the top layer of the CFRP composite, it should only be qualitatively interpreted herein according to the experimental phenomenon as it should have included the complex ionization details.

\section{Conclusions}

Laser ablation behaviors of CFRP laminate have been investigated experimentally and the effects of laser operation modes have been compared. The surface and cross-section morphology is observed through optical microscope. The results revealed that the continuous wave laser made constant ablation of epoxy matrix over several layers and the long duration pulsed wave laser made conical hole through the total laminate thickness. On the contrary, the short duration pulsed wave laser only made ablation of the surface fabric layer without obvious change to the main body of the laminate. It is indicated that most of the incident laser energy would be kept away from the CFRP target once the laser power density is high enough, which might have led to apparent optical breakdown of the ambient gas before the target. It could be concluded that, for the present material parameters and laser wavelength, the laser power flux less than $1.5 \times 10^{12} \mathrm{~W} / \mathrm{m}^{2}$ is appropriate for laser machining of CFRP laminates, while the laser power flux higher than $3.0 \times 10^{13} \mathrm{~W} / \mathrm{m}^{2}$ would be ineffective.

\section{Acknowledgment}

This work was supported by the National Natural Science Foundation of China (Grant no. 11332011). Thanks are also due to X.X. Cheng and Y.C. Yuan from CAS for the assistance with the experimental operations.

\section{References}

[1] Soutis C. Fibre reinforced composites in aircraft construction. Prog Aerosp Sci 2005;41(2):143-51.

[2] Davim JP, Reis Pedro. Study of delamination in drilling carbon fiber reinforced plastics (CFRP) using design experiments. Compos Struct 2003;59(4):481-7.

[3] Li ZL, Zheng HY, Lima GC, Chu PL, Li L. Study on UV laser machining quality of carbon fibre reinforced composites. Compos Part A 2010;41:1403-8.

[4] Lima MSF, Sakamoto JMS, Simoes JGA, Riva R. Laser processing of carbon fiber reinforced polymer composite for optical fiber guidelines. Phys Procedia 2013;41:572-80.

[5] Rodden WSO, Kudesia SS, Hand DP, Jones JDC. A comprehensive study of the long pulse Nd:YAG laser drilling of multi-layer carbon fibre composites. Opt Commun 2002;210:319-28.

[6] Negarestani Reza, Li Lin, Sezer HK, Whitehead David, Methven James. Nanosecond pulsed DPSS Nd:YAG laser cutting of CFRP composites with mixed reactive and inert gases. Int J Adv Manuf Technol 2010;49:553-66.

[7] Madhukar Yuvraj K, Mullick Suvradip, Shukla Dinesh K, Kumar Shailesh, Nath Ashish K. Effect of laser operating mode in paint removal with a fiber laser. Appl Surf Sci 2013;264:892-901.

[8] Sankaranarayanan S, Emminger H, Kar A. Energy loss in the plasma during laser drilling. J Phys D: Appl Phys 1999;32:1605-11.

[9] Thiyagarajan Magesh, Thompson Shane. Optical breakdown threshold investigation of $1064 \mathrm{~nm}$ laser induced air plasmas. J Appl Phys, 111; 2012. p. 073302.

[10] Ali AW. On laser air breakdown, threshold power and laser generated channe length. NRL memorandum report 5187, AD-A 133211.

[11] Kroll Norman, Watson Kenneth M. Theoretical study of ionization of air by intense laser pulses. Phys Rev A 1972;5(4):1883-905.

[12] Cheng J, Liu CS, Shang S, Liu D, Perrie W, Dearden G, Watkins K. A review of ultrafast laser materials micromachining. Opt Laser Technol 2013;46:88-102.

[13] Tavassoli SH, Gragossian A. Effect of sample temperature on laser-induced breakdown spectroscopy. Opt Laser Technol 2009;41:481-5.

[14] Michael K, Iain B, James DL, Claude P. Plasma generation and plume expansion for a transmission-mode microlaser ablation plasma thruster. J Appl Phys 2004;96(1):49-56.

[15] Mathew Jose, Goswami GL, Ramakrishnan N, Naik NK. Parametric studies on pulsed Nd:YAG laser cutting of carbon fibre reinforced plastic composites. J Mater Process Technol 1999;89-90:198-203.

[16] Voisey KT, Fouquet S, Roy D, Clyne TW. Fibre swelling during laser drilling of carbon fibre composites. Opt Laser Eng 2006;44:1185-97.

[17] Chen G, Zhang M, Zhao Z, Zhang Y, Li S. Measurements of laser-induced plasma temperature field in deep penetration laser welding. Opt Laser Technol 2013;45:551-7. 